\title{
SELECTIVE AND NON-EXTRACTIVE SPECTROPHOTOMETRIC DETERMINATION OF CEFDINIR IN FORMULATIONS BASED ON DONOR-ACCEPTOR COMPLEX FORMATION
}

\author{
Babita K. Singh* e Dilip V. Parwate \\ Department of Chemistry, RTM Nagpur University Campus, Nagpur, India \\ Seema Srivastava \\ Central Forensic Science Laboratory, Ramanthapur, Hyderabad, India \\ Sudhir. K. Shukla \\ Central Forensic Science Laboratory, Chandigarh, India
}

Recebido em 29/9/09; aceito em 22/3/10; publicado na web em 30/7/10

\begin{abstract}
Cefdinir has broad spectrum of activity and high prescription rates, hence its counterfeiting seems imminent. We have proposed a simple, fast, selective and non-extractive spectrophotometric method for the content assay of cefdinir in formulations. The method is based on complexation of cefdinir and Fe under reducing condition in a buffered medium $(\mathrm{pH} 11)$ to form a magenta colored donoracceptor complex $\left(\lambda_{\max }=550 \mathrm{~nm}\right.$; apparent molar absorptivity $\left.=3720 \mathrm{~L} \mathrm{~mol}^{-1} \mathrm{~cm}^{-1}\right)$. No other cephalosporins, penicillins and common excipients interfere under the test conditions. The Beer's law is followed in the concentration range 8-160 $\mu \mathrm{g} \mathrm{mL} \mathrm{m}^{-1}$.
\end{abstract}

Keywords: cefdinir; donor-acceptor complex; spectrophotometry.

\section{INTRODUCTION}

Due to counterfeiting, the drug quality has become a source of major concern worldwide, particularly in many developing countries. The most commonly counterfeited drugs are anti-infectives or antibiotics. Use of poor quality antibiotics bears serious health implications such as treatment failure, adverse reactions, drug resistance, increased morbidity, and mortality. ${ }^{1}$ Among antibiotics, cephalosporins are much recently introduced, widely prescribed and costlier. Therefore, incentive to produce their counterfeits because of profit margin increases considerably.

Cefdinir is a third-generation cephalosporin. It has broad spectrum of activity, excellent therapeutic action against susceptible bacteria, and relatively high price. The official monograph of the drug is presently available only in Japanese Pharmacopoeia (2001). The official method for the content assay is a gradient elution RP-HPLC method. In literature, some other RP-HPLC methods have been reported for the analysis of cefdinir in formulations, ${ }^{2,3}$ biological samples, ${ }^{4}$ and few methods also offer separation of drug from related impurities. ${ }^{5,6}$ Liquid chromatography electrospray ionization tandem mass spectrometry has been reported for analysis of the drug in human plasma ${ }^{7}$ and environmental samples. ${ }^{8}$ Other methods of analysis available in the literature are based on square wave stripping voltammetry, ${ }^{9}$ differential pulse voltammetry ${ }^{10}$ and spectrofluorimetry. ${ }^{11}$ These sophisticated instrumental methods are not suitable for counterfeit drug assay as they are expensive and cannot be used in the field. A simple, inexpensive, selective and rugged visible spectrophotometric would be more appropriate for the analysis of counterfeits. The spectrophotometric methods reported in the literature for the analysis of cefdinir are based on UV measurement, ${ }^{12-14}$ a method involving oxidation of cefdinir with excess of $\mathrm{N}$-bromosuccinimide and estimating unreacted $\mathrm{N}$ bromosuccinimide either with celestine blue or $p$-N-Methyl amino phenol sulfate - sulfanilamide, ${ }^{15}$ a method based on reduction of ferric ion with cefdinir and complexation of resultant ferrous ions with 1, 10-phenanthroline to form a blood-red chromogen, ${ }^{16}$ and

*e-mail: singhbab2001@ @ rediffmail.com reaction of cefdinir with Folin-Ciocalteu reagent under alkaline condition to from a blue colored chromogen. ${ }^{14,16}$ The UV spectrophotometric method, although sensitive, are not suitable for the analysis of counterfeits due to lack of selectivity. All visible spectrophotometric methods reported are indirect and lack selectivity because a third generation cephalosporin cefixime, which is structurally similar to cefdinir, has been reported to form identical chromogens in presence of ferric: 1,10-Phenanthroline ${ }^{17}$ and FolinCiocalteu under alkaline condition. ${ }^{18}$

In this study, we have developed a selective non-extractive visible spectrophotometric method based on the formation of donoracceptor complex between cefdinir and Fe. The complex has an intense magenta color. The optimum $\mathrm{pH}$ and other conditions for the formation of complex were determined. The proposed method offers high selectivity as even cefixime do not interfere with the estimation.

\section{EXPERIMENTAL}

\section{Apparatus}

The spectrophotometric measurements were made on Cintra 10e UV-visible spectrophotometer (GBC, Australia).

\section{Reagents}

Cefdinir working standard was gifted by Orchid Pharmaceuticals, Chennai. The purity estimated and supplied by the manufacturer using chromatographic method was $98.79 \%$. It was used without further processing. The tablet samples were purchased from a local chemist shop. All chemicals used were of analytical-grade and procured from Ranbaxy (India). Deionised water was used for preparing solutions. Cefdinir stock solution of $800 \mu \mathrm{g} \mathrm{mL}^{-1}$ was prepared by transferring accurately weighed $40 \mathrm{mg}$ cefdinir to a $50 \mathrm{~mL}$ calibrated volumetric flask and dissolving the solid in $1 \mathrm{mM} \mathrm{NaOH}$. The reagents prepared were $2 \mathrm{mg} \mathrm{mL}^{-1}$ ferrous ammonium sulfate and $0.1 \mathrm{M}$ sodium dithionite (both freshly prepared; $\mathrm{pH}$ of dithionite solution was adjusted at 7). For preparing 0.1 $\mathrm{M}$ phosphate buffer, $3.549 \mathrm{~g} \mathrm{Na}_{2} \mathrm{HPO}_{4}$ was 
dissolved in water and its $\mathrm{pH}$ was adjusted to 11 with $0.1 \mathrm{~N} \mathrm{NaOH}$ using a calibrated $\mathrm{pH}$ meter (Elico, India). The final volume of the buffer was made up to $500 \mathrm{~mL}$.

\section{Method validation}

\section{Calibration plot}

To different aliquots $(0.05$ to $1 \mathrm{~mL})$ of cefdinir stock solution $1 \mathrm{~mL}$ dithionite, $2 \mathrm{~mL}$ phosphate buffer $(\mathrm{pH} 11 ; 0.1 \mathrm{M})$ and $0.5 \mathrm{~mL}$ ferrous ammonium sulfate were added and final volume was adjusted to $5 \mathrm{~mL}$ with deionised water. The solutions were allowed to stand for $20 \mathrm{~min}$ and later absorbances were measured at $550 \mathrm{~nm}$ against a reagent blank prepared in the same manner.

\section{Tablet analysis and recovery study}

Twenty tablets were finely powdered. An amount of tablet equivalent to $20 \mathrm{mg}$ of cefdinir was weighed accurately and transferred to a $50 \mathrm{~mL}$ volumetric flask. The powder was dissolved in $1 \mathrm{mM} \mathrm{NaOH}$ by mechnaical shaking or sonication for $10 \mathrm{~min}$. After dissolution, the solution filtered using Whatman 41 filter paper, this is the stock solution of the tablet sample. To $0.5 \mathrm{~mL}$ of this stock solution $1 \mathrm{~mL}$ dithionite, $2 \mathrm{~mL}$ phosphate buffer $(\mathrm{pH} 11 ; 0.1 \mathrm{M})$ and $0.5 \mathrm{~mL}$ ferrous ammonium sulfate were added; the final volume was made $5 \mathrm{~mL}$ with deionised water. The measurement was performed on six replicates using the general procedure.

The tablet sample was spiked separately with the working standard of cefdinir corresponding to 100 and $200 \%$ label claim, and then analyzed by the procedure described for the tablet analysis. This is done to check for the recovery of the drug at different concentration levels in formulations.

\section{Characterization of complex}

\section{Job's and Mole ratio method for determining stoichiometry of complex}

The stoichiometry of complex was determined by both Job's method and Mole ratio method. A $0.01 \mathrm{M}$ dithionite solution and phosphate buffer ( $\mathrm{pH} 11 ; 0.1 \mathrm{M})$ were employed in both the methods.

In case of Job's method, a $1.25 \mathrm{mM}$ standard solution of cefdinir and $1.25 \mathrm{mM}$ solution of ferrous ammonium sulfate were used. A series of solutions was prepared in which the total volume of cefdinir and ferrous ammonium sulfate was kept $2 \mathrm{~mL}$, but their proportion was varied between 1:19 and 19:1. To all the systems $2 \mathrm{~mL}$ phosphate buffer and $1 \mathrm{~mL}$ sodium dithionite were added and the general procedure was followed.

A $1.25 \mathrm{mM}$ standard solution of cefdinir and $0.125 \mathrm{mM}$ ferrous ammonium sulfate solution were used in mole ratio method. A series of solutions was prepared, in which $2 \mathrm{~mL}$ of ferrous ammonium sulfate was used throughout, but the volume of cefdinir was varied to get Fe:Cefdinir ratio between 1:0.25 to 1:10. To all systems $1 \mathrm{~mL}$ sodium dithionite and $2 \mathrm{~mL}$ phosphate buffer were added. The final volume was adjusted to $5 \mathrm{~mL}$ with water. Thereafter, the general procedure was followed.

\section{Spectroscopic studies for structure determination}

The complex species formed is highly polar and cannot be extracted with organic solvents. In order to accomplish extraction, $\mathrm{K}_{2} \mathrm{CO}_{3}$ was used as "salting-out" agent. An excess of $\mathrm{K}_{2} \mathrm{CO}_{3}$ decreases activity of "free" water, this allows use of ethanol as extractant. ${ }^{19}$ The crystalline product obtained is stable over a week when stored in the dark. In sunlight, the complex decomposes readily in a day as determined by the diffuse reflectance measurement made on the complex.

\section{Mössbauer spectroscopy}

The Mössbauer instrument is locally fabricated by Nucleonix, India. The instrument has a gas filled proportional counter as detector and it has 512 channel analyser. The crystalline sample was powdered and screened through 100 mesh sieve. The sample was sealed in the sample holder with a cellophane film. The measurement was made in transmission geometry at the room temperature. The calibration was performed with natural $\alpha$-Fe. The experimental data obtained was evaluated by Lorentzian curve fitting.

\section{Electron proton resonance spectroscopy}

The ESR (Electron spin resonance) measurement was performed on a Varian E-112 spectrometer using X-band microwave frequency with the sensitivity of $5 \times 10^{10}$ spins. The ESR spectrometer settings for the study were as follows: Modulation frequency $=100 \mathrm{kHz}$; modulation amplitude $=1$ Gauss, microwave frequency $=9.1 \mathrm{GHz}$, microwave power $=5 \mathrm{~mW}$, receiver gain $=2 \times 10^{3}$.

\section{RESULTS AND DISCUSSION}

Cefdinir is known to be interfered by Fe supplements, which sometimes may render red or pink color to urine and stools. The appearance of color is due to the formation of a stable complex between ferrous ion and cefdinir. In the proposed method, cefdinir has been shown to form an intense magenta complex with Fe in alkaline medium under reducing conditions having absorption maxima at $550 \mathrm{~nm}$ (Figure 1A).

\section{Stability of complex}

The results of kinetic study indicate that the time required to reach equilibrium of complexation reaction is $20 \mathrm{~min}$. The complex is stable up to $50 \mathrm{~min}$ as there is $5 \%$ reduction in absorbance at 60 min. Therefore, all measurements were carried out between 20 and $50 \mathrm{~min}$. The fading of color of the complex on prolonged standing is due to alkaline hydrolysis of cefdinir.

\section{Selection of reducing agent}

Due to fast oxidation of ferrous to ferric in presence of sunlight, the stability of complex is affected. Thus, some reducing agent is required to enhance the stability of complex. Various reducing agents viz stannous chloride, thiomalic acid and sodium dithionite served the purpose. Sodium dithionite was found most suitable as it has sufficient reducing action in the neutral and alkaline condition. Stannous chloride is readily soluble in highly alkaline solution, but it has limited solubility at $\mathrm{pH} \leq 11$. To estimate optimum dithionite concentration required to circumvent oxidation of Fe II various systems containing Fe: dithionite in the mole ratio between 1:1 and 1:100 were prepared. The stability was maximum when the Fe:dithionite mole ratio lies in the range 1:5 to 1:50. For further studies, we fixed the Fe: dithionite mole ratio at 1:40 because at this level dithionite effectively reduces ferric to ferrous as well as eliminate $\mathrm{Fe}(\mathrm{OH}){ }_{2}$ precipitation that might cause deviation due to dispersion of light.

\section{Effect of pH}

The effect of $\mathrm{pH}$ on formation of the complex is depicted in Figure 1B. There are two plateaus in the curve. Thus, the complex formation is a two step process. In the first step around $\mathrm{pH} 8.0$ a faint pink color was obtained. The complex turns to magenta color subsequently around $\mathrm{pH}$ 9.7. The inflexion in the curve at $\mathrm{pH} 9.7$ represent deprotonation of the oxime function. Although the complex 
formation completes before deprotonation of oxime, the development of bright and intense magenta color occurs only after deprotonation of oxime group.

The anion in buffer solution may interfere as Fe II complexes with many inorganic anions. Therefore, the stability of complex was assessed in various buffer solutions of $\mathrm{pH} 11$ viz $0.05 \mathrm{M}$ Borax/ 0.1 $\mathrm{M} \mathrm{NaOH}(1: 1, \mathrm{v} / \mathrm{v}), 0.1 \mathrm{M} \mathrm{NaHCO}_{3} / 0.091 \mathrm{M} \mathrm{NaOH}(1: 1, \mathrm{v} / \mathrm{v}), 0.1$ $\mathrm{M} \mathrm{Na}_{2} \mathrm{HPO}_{4} / 0.0164 \mathrm{M} \mathrm{NaOH}(1: 1, \mathrm{v} / \mathrm{v})$ and a $\mathrm{pH} 12$ buffer solution of $0.1 \mathrm{M} \mathrm{KCl} / 0.012 \mathrm{M} \mathrm{NaOH}(1: 1, \mathrm{v} / \mathrm{v})$. The stability of complex was not affected by carbonate, phosphate or chloride anions furnished by the respective buffers. For further study, pH 11 phosphate buffer was employed.

\section{Selectivity}

The selectivity of the method for cefdinir under experimental condition is most remarkable as no other cephalosporins, congener penicillins and excipients commonly formulated with the drug interfere with the estimation.

Usually, cephalosporins and pencillins complex with Fe through $\mathrm{N}$ and $\mathrm{S}$ donors on dihydrothiazine and thioazolidene rings respectively, but such complexes have very low stability. According to our hypothesis, the complexation in cefdinir is mainly due to presence of oxime function, and $\mathrm{N}$ on thiazole ring is also involved. The resultant complex species is considerably stable. Behavior of other cephalosporins possesing thiazole ring viz cefixime, cefetamet and cefempidone, but differing from cefdinir in the sense that they possess caroboxymethoxy imino, methoxy imino and oxopyrrolidin3-yloxyimino groups respectively, instead of oxime group have been tested. None of them formed color complex with Fe, thus upholding the validity of our hyothesis.

The excipients like starch, cellulose, lactose, titanium dioxide, polyethylene glycol and magnesium sterate, which are commonly formulated with cefdinir do not interfere.

\section{Quantitative analysis}

Under the experimental conditions described earlier, the standard calibration curve was plotted. The concentration of the complex exhibited linear relationship with absorbance, and the regression analysis on Beer's law plot revealed good correlation $(r=0.9993)$. The Beer's law range, Ringbom range, molar absorptivity, Sandell's sensitivity and other statistical parameters were calculated, and provided in Table 1 . The method is sufficiently sensitive for the analysis of cefdinir.

Table 1. Optical characteristics, regression analysis, accuracy and precision of the proposed method for the analysis of cefdinir

\begin{tabular}{lc}
\hline Parameters & Observed values \\
\hline$\lambda_{\text {max }}(\mathrm{nm})$ & 550 \\
Beer's law limit $\left(\mu \mathrm{g} \mathrm{mL}{ }^{-1}\right)$ & $8-160$ \\
Ringbom concentration range $\left(\mu \mathrm{g} \mathrm{mL}^{-1}\right)$ & $17-70$ \\
Apparent molar absorptivity $\left(\mathrm{L} \mathrm{mole}^{-1} \mathrm{~cm}^{-1}\right)$ & 3720 \\
Sandell's sensitivity $\left.\left(\mu \mathrm{g} \mathrm{cm}{ }^{-2} \text { per } 0.001 \mathrm{absorbance} \mathrm{unit}\right)^{-1}\right)$ & 0.108 \\
$\mathrm{LOD}\left(\mu \mathrm{g} \mathrm{mL}^{-1}\right)$ & 0.56 \\
LOQ $(\mu \mathrm{g} \mathrm{mL})$ & 1.71 \\
Standard deviation \% & 0.66 \\
Range of error \% & \pm 2.2 \\
Linear regression equation $(A=m C+b)$ & \\
Slope or specific absorptivity $(m)$ & 0.0093 \\
Intercept $(b)$ & 0.0462 \\
Correlation coefficient $(r)$ & 0.9993 \\
\hline
\end{tabular}

${ }^{\mathrm{a}}$ For filter photometric analysis

\section{Method validation}

The samples of pure drug were prepared and tested at three concentration levels $\left(20,40\right.$ and $\left.100 \mu \mathrm{g} \mathrm{mL}^{-1}\right)$ of cefdinir using the proposed spectrophotometric method. The complete set of validation assay was performed. The results obtained for pure drug are given in Table 2 . The precision and accuracy were determined by performing six replicate measurements at each concentration level. The relative standard deviation, standard average error and confidence limit (95\% level) were calculated (Table 2). The method is sufficiently accurate and precise for quantitation purpose.

Table 2. Evaluation of accuracy and precision of the proposed method for the analysis of cefdinir $(n=6)$

\begin{tabular}{lcccc}
\hline $\begin{array}{l}\text { Drug content }\left(\mu \mathrm{g} \mathrm{mL}^{-1}\right) \\
\text { Taken }\end{array}$ & Found & RSD \% & $\begin{array}{c}\text { Standard average } \\
\text { error \% }\end{array}$ & $\begin{array}{c}\text { Confidence } \\
\text { limit }\end{array}$ \\
\hline 20.0 & $19.92 \pm 0.27$ & 1.37 & 0.22 & $19.92 \pm 0.234$ \\
40.0 & $39.27 \pm 0.16$ & 0.41 & 0.73 & $39.27 \pm 0.137$ \\
100.0 & $100.29 \pm 0.76$ & 0.76 & 0.65 & $100.29 \pm 0.649$ \\
\hline
\end{tabular}

\section{Tablet analysis and recovery study}

Two different brands of tablet samples were analysed. The proposed method when used for extraction and subsequent estimation of cefdinir from tablets after spiking with 100 and $200 \%$ of the drug working standard afforded recovery of 99.11 to $101.32 \%$. The results shown in Table 3 confirmed that there is no loss of drug during sample solution preparation and the method is not liable to interference by excipients usually formulated with cefdinir. The proposed method is sensitive, selective, and simple in terms of reagent requirement and methodology. Therefore, it is convenient for the quantitative analysis of both pure drug and tablet formulations.

Table 3. Tablet analysis and recovery study $(n=6)$

\begin{tabular}{|c|c|c|c|c|c|}
\hline $\begin{array}{l}\text { Pharmaceutical } \\
\text { formulation }\end{array}$ & 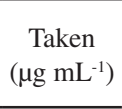 & $\begin{array}{l}\text { Standard added } \\
\left(\mu \mathrm{g} \mathrm{mL} \mathrm{mL}^{-1}\right)\end{array}$ & $\begin{array}{l}\text { Examined } \\
\text { drug, found } \\
\left(\mu \mathrm{g} \mathrm{mL} \mathrm{mL}^{-1}\right)\end{array}$ & $\begin{array}{c}\mathrm{RSD} \\
\%\end{array}$ & $\begin{array}{c}\text { Recovery } \\
\%\end{array}$ \\
\hline \multirow{3}{*}{$\begin{array}{l}\text { Oceph }^{\mathrm{a}} \\
(300 \mathrm{mg} / \text { tablet })\end{array}$} & \multirow[t]{3}{*}{40} & 0 & $39.64 \pm 0.16$ & 0.40 & 99.11 \\
\hline & & 40 & $79.65 \pm 0.73$ & 0.92 & 100.02 \\
\hline & & 80 & $119.53 \pm 0.60$ & 0.50 & 99.85 \\
\hline \multirow{3}{*}{$\begin{array}{l}\text { Kefnir }^{\mathrm{b}} \\
\text { (300 mg/tablet) }\end{array}$} & \multirow[t]{3}{*}{40} & 0 & $40.14 \pm 0.39$ & 0.97 & 100.35 \\
\hline & & 40 & $80.37 \pm 0.89$ & 1.11 & 100.57 \\
\hline & & 80 & $121.19 \pm 0.37$ & 0.30 & 101.32 \\
\hline
\end{tabular}

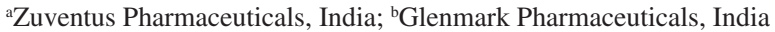

\section{Characterization of complex}

The results of Job's and mole ratio method are shown in Figure 1C and 1D respectively. A single maxima in Job's method plot and two straight intersecting portions in mole ratio curve indicate that a single complex species is formed in the binary system and its composition is Fe:Cefdinir $=1: 2$. The value of overall stability constant determined from the Job's method plot is $1.5 \times 10^{9} \mathrm{~L}^{2} \mathrm{~mole}^{-2}$.

The zero field Mössbauer spectrum recorded (Figure 2) at the room temperature gives isomer shift, $\delta=0.32 \mathrm{~mm} \mathrm{~s}^{-1}$ (w.r.t $\alpha$-Fe) and quadrapole splitting, $\left|\Delta \mathrm{E}_{\mathrm{O}}\right|=1.54 \mathrm{~mm} \mathrm{~s}^{-1}$. This indicates presence of ferric species in octahedral high spin $3 \mathrm{~d}\left(\mathrm{t}_{2 \mathrm{~g}}\right)^{3}\left(\mathrm{e}_{\mathrm{g}}\right)^{2}$ configuration. ${ }^{20}$ Further, 'the ESR measurement made on the complex has a single line ( $g=1.9778$ ). The single line is due to $-1 / 2$ to $+1 / 2$ transition, other fine structure lines were not visible. The $g$ value is very close to free spin value and isotropic indicating presence of $\mathrm{Fe}^{3+}\left(\mathrm{d}^{5}\right)$ in a cubic 

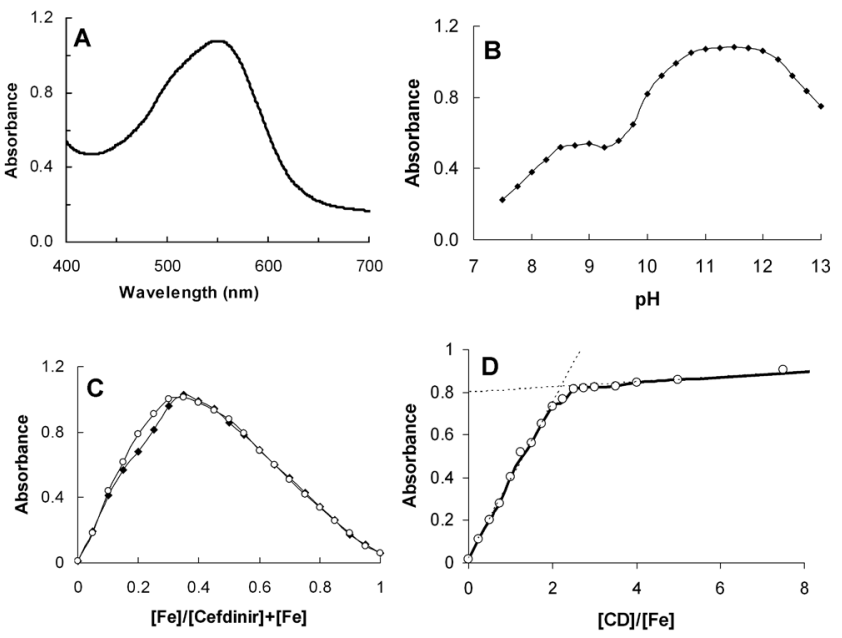

Figure 1. Formation of cefdinir-Fe complex: A) Visible absorption spectrum in $\mathrm{pH} 11$ phosphate buffer medium. B) Effect of $\mathrm{pH}$ of medium on stability. C) Job's method plot for determining stoichiometry. D) Mole ratio plot for determining stoichiometry

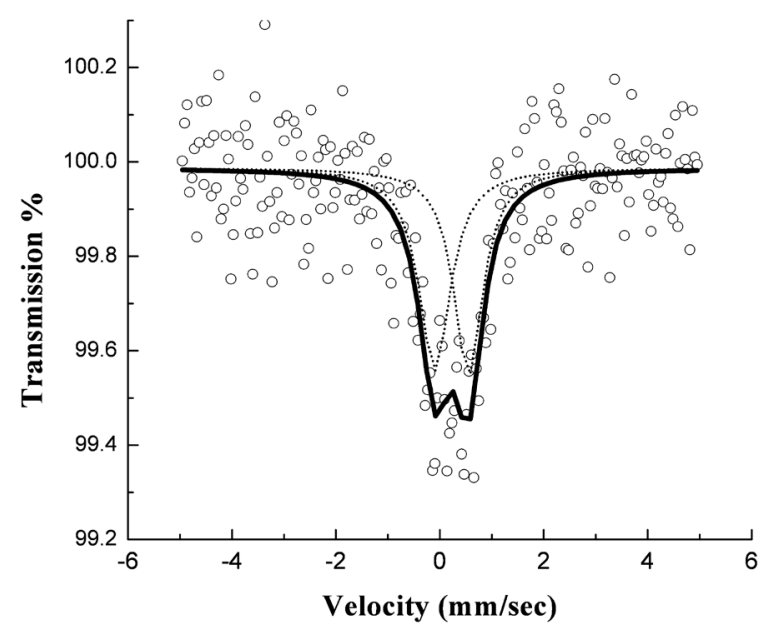

Figure 2. Zero field ${ }^{57} \mathrm{Fe}$ Mössbauer spectrum of cefdinir and Fe complex recorded at room temperature in transmission geometry. The solid line through data was obtained by lorentzian curve fitting

field. The ESR result corroborates with the findings of Mössbauer spectrum analysis. The negative deviation of $g$ value from free spin value indicates that the metal ligand bond has fair amount of covalent nature. ${ }^{21}$ The revelation that oxidation state of $\mathrm{Fe}$ is $3+$ in the complex is conflicting with our presumption. According to our presumption, the oxidation state of $\mathrm{Fe}$ is $2+$ in the complex, which is justified by the fact that under the highly reducing condition created by adding dithionite the existence of ferric species is improbable. However, if we assume that after complexation the $\mathrm{Fe}$ donates one electron to $\mathrm{O}$ (through $\mathrm{N}$ ) on oxime function, then the ESR and Mössbauer spectroscopic behavior holds consistent with our presumption. The validity of this assumption is strengthened by the fact that the molar absorptivity of complex is $3720 \mathrm{~L} \mathrm{~mole}^{-1} \mathrm{~cm}^{-1}$, which can only be due to donor-acceptor complex formation because the absorption band due to forbidden $\mathrm{d}$-d transition are very weak. The proposed structure of complex and its formation scheme is shown in Figure 3.

\section{CONCLUSIONS}

The proposed method is simple, fast and at the same time fairly
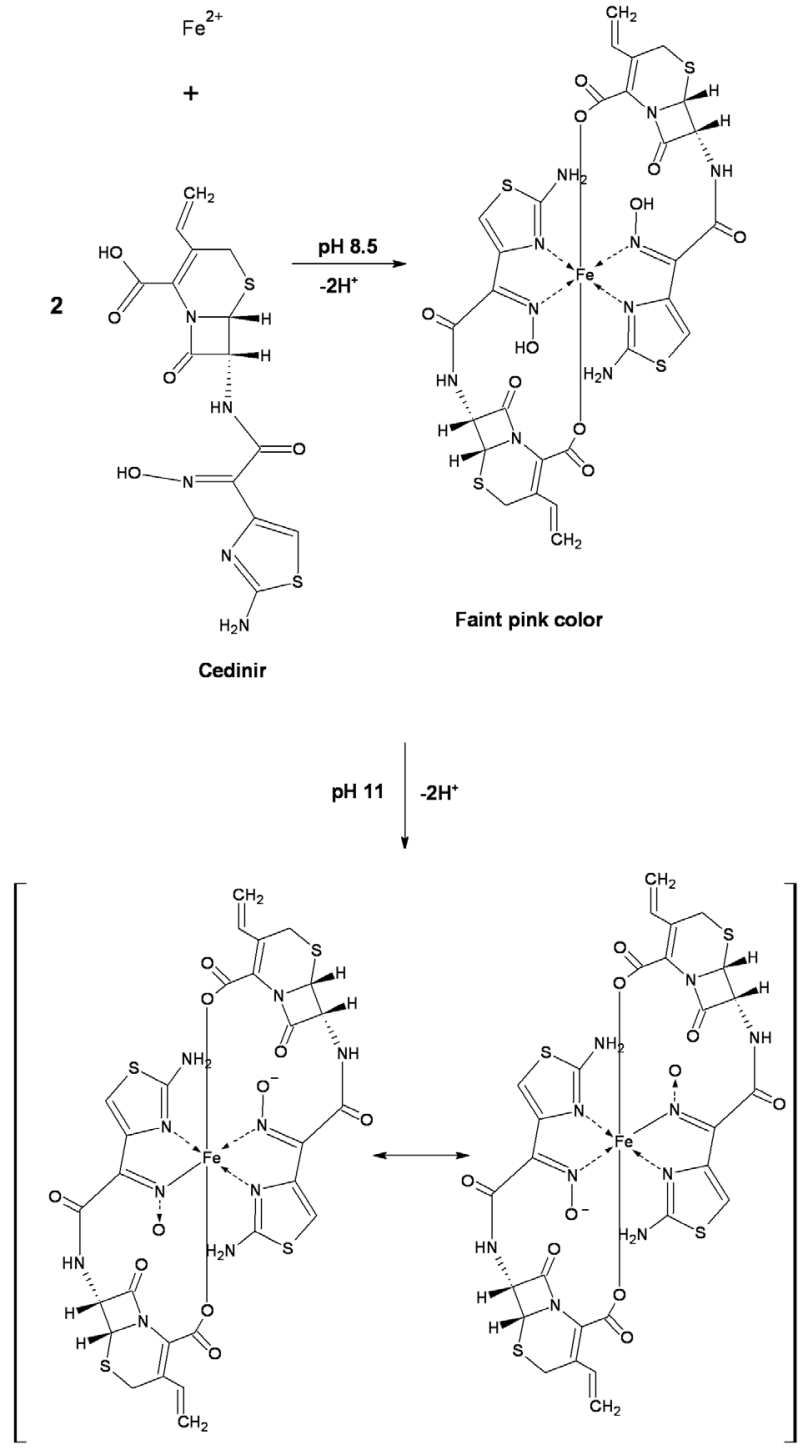

Magenta color

Figure 3. Complexation between cefdinir and $\mathrm{Fe}$; $\mathrm{pH}$ dependence of complex structure and color

accurate and precise. With these virtues, it is suitable for quantitation of drugs in counterfeit formulations. The chemicals and reagent requirement is minimal. The quantitative assay in field can be accomplished with a simple filter photometer. The selectivity of test for cefdinir under the given condition is most remarkable, as none of the cephalosporins including cefixime, congener penicillins and excipients would interfere. The only apparent limitation is due to the stability of reagents as ferrous ammonium sulfate slowly oxidizes and dithionite decomposes in presence of sunlight. However, this limitation can be overcome by either storing reagents in the dark or by using freshly prepared reagents.

\section{ACKNOWLEDGMENTS}

The authors thank Head, Department of Chemistry, RTM Nagpur University for providing laboratory facilities. The authors thank Prof. C. Bansal, School of Physics, University of Hyderbad for Mössbauser spectroscopic measurment and SAIF, IIT Mumbai for recording ESR spectrum. One of the authors Ms. Babita Singh want to thank Central Forensic Science Laboratory, Directorate of Forensic Science, Ministry of Home Affairs, Hyderabad, India for providing her fellowship. 


\section{REFERENCES}

1. United States Pharmacopeia Drug Quality and Information Program. 2004. A review of drug quality in Asia with focus on anti-infectives, United States Pharmacopoeia, Drug Quality and Information Program $1-46$.

2. Sankar, D. G.; Priya, K. D.; Krishna, M. V.; Latha, P. V. M.; Acta Ciencia Indica 2004, 30, 273.

3. Gandhimathi, M.; Suganthi, A.; Ravi, T. K.; Pattasseril, M. B.; Indian J. Pharm. Sci. 2004, 66, 248.

4. Hadad, G. M.; Emara, S.; Mahmoud, W. M. M.; Chromatographia 2009 $70,1593$.

5. Mehta, T. N.; Subbaiah, G.; Pundarikakshudu, K.; J. AOAC Int. 2005, 88, 1661.

6. Okamoto, Y.; Itoh, K.; Namiki, Y.; Matsushita, J.; Fujioka, M.; Yasuda, T.; J. Pharm. Biomed. Anal. 1996, 14, 739.

7. Chen, Z. J.; Zhang, J.; Yu, J. C.; Cao, G. Y.; Wu, X. J.; Shi, Y. G.; J. Chromatogr., B: Anal. Technol. Biomed. Life Sci. 2006, 834, 163.

8. Nageswara Rao, R.; Venkateswarlu, N.; Narsimha, R.; J. Chromatogr., A 2008, 1187, 151.

9. Jain, R.; Radhapyari, K.; Jadon, N.; J. Electrochem. Soc. 2007, 154, F199.
10. Tao, F.; Yu, Z.; Han, X.; Zheng, S.; Dong, S.; Yaowu Fenxi Zazhi 2008, $28,1512$.

11. Suganthi, A.; Shrikumar, S.; Pattesseril, M. B.; Umamaheswari, M.; Ravi, T. K.; Indian J. Pharm. Sci. 2004, 66, 689.

12. Sankar, D. G.; Sudarshan, M.; Krishna, M. V.; Latha, P. V. M.; J. Inst. Chem. (India) 2005, 77, 5.

13. Patil, S. S.; Kasture, P. V.; Indian Pharmacist 2008, 7, 110.

14. Shah, P. B.; Pundarikakshudu, K.; Indian J. Pharm. Sci. 2004, 66, 665.

15. Srinivas, L. D.; Prasad Rao, K. V. S.; Sastry, B. S.; Int. J. Chem. Sci. (India) 2005, 3, 353.

16. Sankar, D. G.; Surekha, M. L.; Krishna, M. V.; Latha, P. V. M.; Int. J. Chem. Sci. (India) 2005, 3, 499.

17. Al-Momani, I. F.; J. Pharm. Biomed. Anal. 2001, 25, 751.

18. Sankar, D. G.; Sushma, K.; Lakshmi, R. V.; Reddy, M. N.; Murthy, T. K.; Rao, S. Y.; Indian Drugs 2001, 38, 617.

19. Karger, B. L.; Synder, L. R.; Horvath, C.; An Introduction to Separation Science, Wiley: USA, 1973.

20. Huynh, H. H; Kent, T. A In Advances in Mössbauer Spectroscopy; Thosar, B. V.; Iyengar, P. K., eds.; Elsevier, 1983.

21. Abragam, A; Bleaney, B.; Electronic paramagnetic resonance of transition ions, Clarendon Press: Oxford, 1970. 